\title{
MicroCHP Based on the Brayton Microturbine with the Changed Order of Processes for the energy supply in low-rise housing
}

\author{
Andrey A. Zhinov ${ }^{1, *}$, Denis V. Shevelev ${ }^{1}$, and Evgeni G. Lipihin ${ }^{1}$ \\ ${ }^{1}$ Bauman Moscow State Technical University (BMSTU), Kaluga branch, Kaluga, Bazhenova 4, 248000, Russia
}

\begin{abstract}
For autonomous power supply it's suggested to use microCHP (micro combined heat and power plant) based on the Brayton microturbine with the changed order of processes (reversed Brighton cycle). The paper presents the characteristic ranges of thermal and electric power of autonomous consumers in various climate zones and thermodynamic calculations for the two types of microturbine. In the first case, the parameters of the turbine unit are set according to the characteristics of modern vehicles turbochargers, in the second - based on the parameters of modern gas microturbines. The work of microCHP based on the microturbine with the changed order of processes was considered for both traditional and low-temperature heating systems. The electric power of microCHP ranges from 2 to $15 \mathrm{~kW}$, thermal power - from 45 to 160 $\mathrm{kW}$. The peculiarity of MicroCHP is combustion of fuel at atmospheric pressure, which allows the use of natural gas from low-pressure networks, solid fuel, and garbage. It is concluded that this turbine unit is able to solve the problem of electricity and heat supply to most isolated consumers in various climate zones.
\end{abstract}

\section{Introduction}

Traditional systems of centralized electricity and heat supply are based on the use of a relatively small number of high-power plants [1,2]. This ensures sustainable production and distribution of heat and electricity. Currently, the development of power engineering, information and communication technologies makes it possible to create highly reliable power grids (Smart Grid) based on a large number of low-power plants [3]. Solar panels, wind generators, gas piston and gas turbine plants can be used as power generating facilities in the Smart Grid. Such installations can provide electricity and heat to individual residential buildings, townhouses, small office and warehouse premises (low-rise housing).

Despite the relatively low efficiency of power generation, thermal gas piston and gas turbine engines are easy to operate and reliable, as well as their work does not depend on weather conditions and time of a day. On their basis, it is possible to create installations that produce both electrical and thermal energy for the needs of heat supply systems (Combined Heat and Power Generators (CHP)) due to the beneficial use of heat from exhaust gases [4].

The variety of consumers of thermal and electrical energy for distributed energy facilities assumes a wide range of changes in the main parameters of micro CHP.

Table 1 shows the approximate ranges of electrical $N_{e}$ and thermal $N_{t}$ power of microCHP for various climate zones.
Table 1. MicroCHP parameters for isolated consumers.

\begin{tabular}{|l|c|c|c|c|c|}
\hline & \multirow{H}{*}{$\begin{array}{c}\text { Heated } \\
\text { area, } \mathbf{m}^{2}\end{array}$} & $N_{\boldsymbol{e}}$, & \multicolumn{3}{|c|}{$\boldsymbol{N}_{\boldsymbol{t}}, \mathbf{k W}$} \\
\cline { 4 - 6 } & $\begin{array}{c}\text { Subtropi } \\
\mathbf{c s}\end{array}$ & $\begin{array}{c}\text { Temperat } \\
\text { e climate }\end{array}$ & Subarctic \\
\hline $\begin{array}{l}\text { Individual } \\
\text { houses }\end{array}$ & $200 \ldots 250$ & $3 \ldots 5$ & $10 \ldots 25$ & $30 \ldots 35$ & $45 \ldots 70$ \\
\hline $\begin{array}{l}\text { One-and- } \\
\text { two- } \\
\text { bedroom } \\
\text { townhouses }\end{array}$ & $450 \ldots 600$ & $9 \ldots 15$ & $20 \ldots 30$ & $45 \ldots 60$ & $50 \ldots 75$ \\
\hline $\begin{array}{l}\text { Offices, } \\
\text { warehouses }\end{array}$ & $600 . .1000$ & $5 \ldots 10$ & $40 \ldots 60$ & $80 \ldots 100$ & $100 \ldots 120$ \\
\hline
\end{tabular}

The Table 1 shows that to meet the energy needs of the specified categories of users of various climatic conditions, microCHP with thermal and electrical power ratio $N_{t} / N_{e}=5 \ldots .12$ is required. For these purposes, power plants based on gas microturbines are the most suitable ones (Table 2) [5].

Table 2 Parameters of CHP installations based on low power heat engines.

\begin{tabular}{|c|c|c|}
\hline & $\begin{array}{c}\text { Gas piston } \\
\text { engines }\end{array}$ & Gas microturbines \\
\hline $\begin{array}{c}\text { Electric } \\
\text { power } N_{e}, \mathrm{~kW}\end{array}$ & $6 \ldots 20$ & $40 \ldots 1000$ \\
\hline$N_{t} / N_{e}$ & $1.8 \ldots 2.5$ & $1.5 \ldots 6.0$ \\
\hline
\end{tabular}

However, the serial gas microturbines on the market have excessive (for the needs of residential and small 
commercial buildings) electrical power. It's possible to ensure the energy needs of these isolated consumers with the microCHP based on the Brayton microturbine with the changed order of processes (Figure 1). The principle of operation of this scheme is described in [6].

The results of the thermodynamic calculation of the microCHP cycle with the changed order of processes are presented in [6,7], with parameters typical for the mass series of automobile turbochargers (adiabatic efficiency of the turbine $\eta_{t}=0.74$, the adiabatic efficiency of the compressor $\eta_{k}=0.75$, the gas temperature in front of turbine $T_{3}=950 \mathrm{~K}$ ) [8].

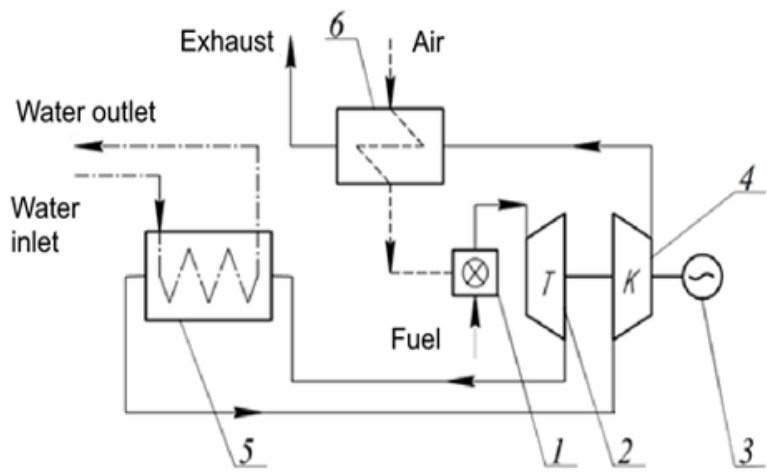

Fig. 1. Scheme of microCHP with Brayton microturbine with the changed order of processes and heat exchangers: 1 atmospheric combustion chamber; 2 - turbine; 3 - power generator; 4 - compressor; 5 - gas-water heat exchanger; 6 - air heater.

It was estimated that in the $\pi_{t}=1.8 \ldots 2.4$ range, microCHP turbo-unit with an electric power of $3 \mathrm{~kW}$ and thermal power of $90 \ldots 120 \mathrm{~kW}$ corresponds to vehicles turbochargers with an air flow rate of $0.1 \ldots 0.25 \mathrm{~kg} / \mathrm{s}$. The maximum efficiency of the cycle $\eta_{e}$ then is $4 \%$, the heat of the burned fuel utilization rate is $\eta_{t}>92 \%$.

\section{Materials and Methods}

For the proposed microCHP scheme with the changed order of processes, it is possible to single out the following main directions for increasing it's efficiency:

- increasing the efficiency of the main elements of the turbomachine - compressor $\eta_{k}$ and turbine $\eta_{t}$;

- increase in gas temperature at the inlet to the turbine $T_{3}$;

- reduction of the temperature head in the heat exchanger $\delta t$ between hot and cold coolants at the outlet of the gas-water heat exchanger;

- reduction of losses of total pressure in the gas-air tract of microCHP.

Taking into account the consumption of the working fluid in the microturbine $(G=0.075 \ldots 0.25 \mathrm{~kg} / \mathrm{s})$ and the current efficiency level of small dimensional turbomachines of $[9,10]$, the efficiency level of the compressor and turbine can be considered at about $78 \%$.

The gas temperature at the entrance to the turbine of common vehicles turbochargers is $900 \ldots 950 \mathrm{~K}$, which enables to use inexpensive materials at their mass production. In the case of applying heat-resistant austenitic alloys on a nickel base, the gas temperature can be increased to $1000 \ldots 1050 \mathrm{~K}$ without any loss in turbo unit resource [11].

The temperature head between the hot and cold heat carriers in the gas-water heat exchanger $\delta t$ can be reduced from the previously taken $10{ }^{\circ} \mathrm{C}$ to $7{ }^{\circ} \mathrm{C}$, which is in accordance with the recommendations [12].

A significant reduction in the total pressure loss in the gas-air path of the microCHP is practically feasible, but it entails an increase in the dimensions of heat exchangers and, consequently, an increase in the mass and dimensions of the microCHP. When performing the thermodynamic calculation, the value of the total recovery coefficient of the total pressure in the gas-air tract $\sigma_{\Sigma}=0,96$ was taken.

To estimate the possible power range and maximum effective efficiency of the microCHP of the proposed scheme, variational calculations of the thermodynamic cycle were made using the GateCycle software [13]. The main initial data are given in Table 3 .

\section{Results}

Figure 2 shows the calculated dependence of microCHP with the changed order of processes on the degree of pressure decrease in the turbine $\pi_{t}$

Figure 3 shows the calculated dependence of the specific work of the microCHP on the degree of pressure decrease in the turbine $\pi_{t}$

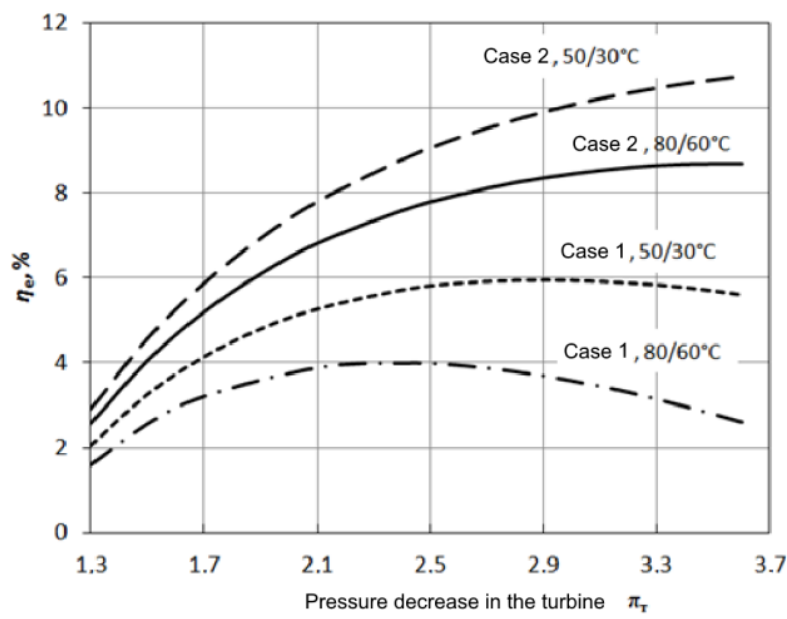

Fig. 2. Dependence of microCHP efficiency $\eta_{e}$ from $\pi_{t}$.

Increasing the efficiency of the compressor and turbine, the initial temperature of the gas in front of the turbine, and reducing the temperature head in the heat exchanger led to an increase in specific work by $50 \%$. 


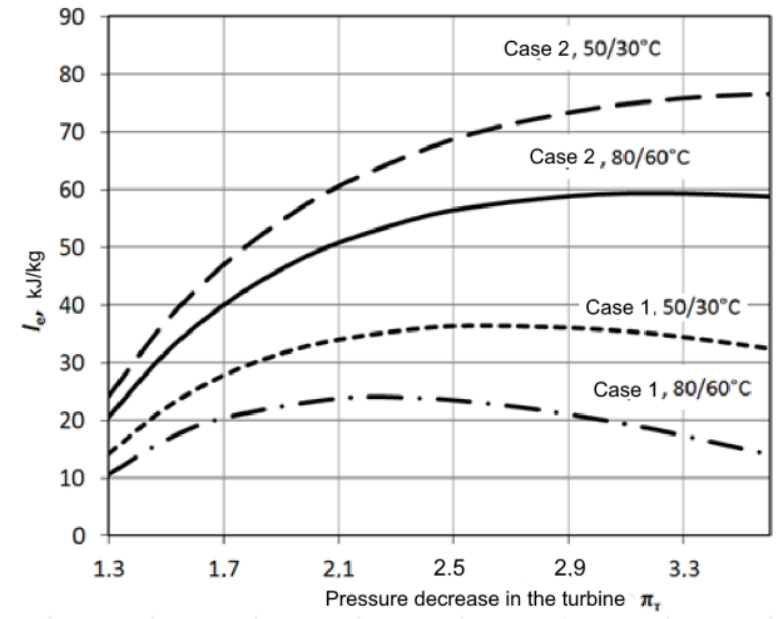

Fig. 3. Dependence of the specific work of the cycle $l_{\mathrm{e}}$ on the degree of pressure decrease in the turbine $\pi_{t}$.

Figures 4 and 5 show the change in the electric $N_{e}$ and the thermal power $N_{t}$, depending on the air flow $G$ in the range typical of vehicles turbochargers. The calculation is carried out for $\pi_{t}=2.4$, which corresponds to the ratio $N_{t} / N_{e}=11$ for the operation of microCHP on the heating system with the temperature of the heat carrier $80 / 60{ }^{\circ} \mathrm{C}$ (Case 1) and $N_{t} / N_{e}=9.5$ for the heating system with the temperature $50 / 30{ }^{\circ} \mathrm{C}$ (Case 2). When determining the electrical power of the microCHP, the efficiency of mechanical into electrical energy conversion $\eta_{m}=0.91$ was additionally considered.

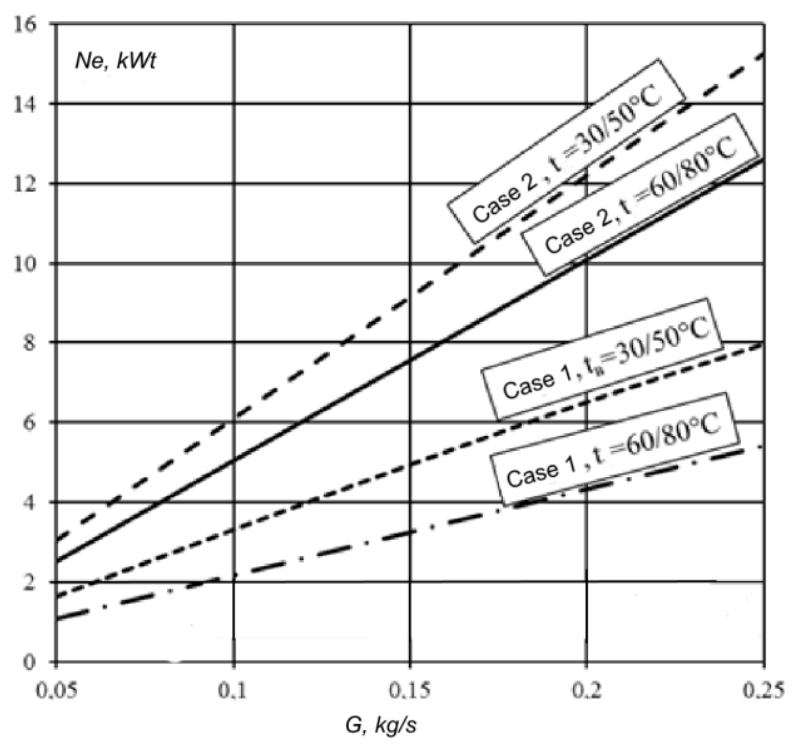

Fig. 4. The range of electric power change in microCHP.

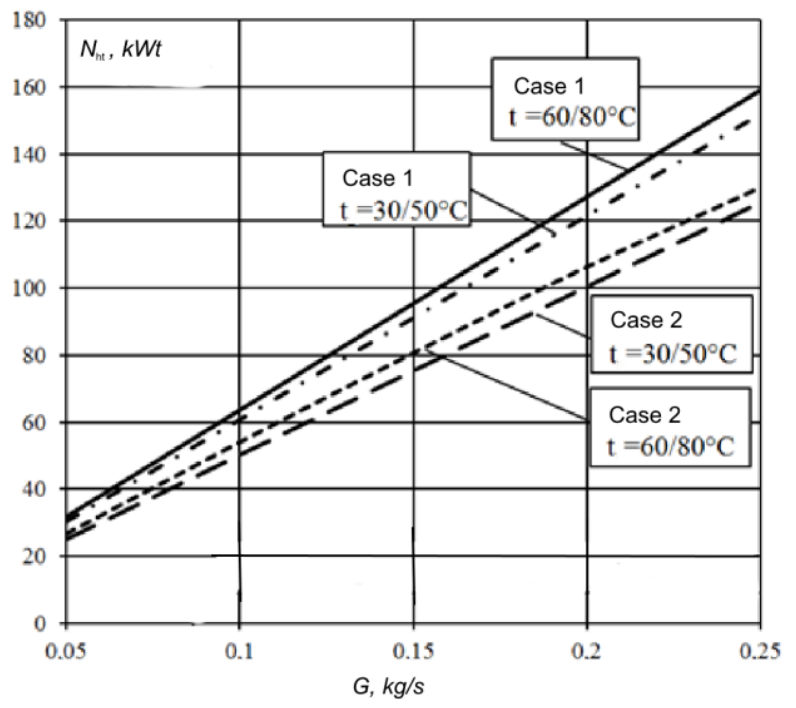

Fig. 5. The range of thermal power change in microCHP.

\section{Discussion}

It is established that for the presented scheme, as well as for the traditional Brighton cycle, the dependence of the efficiency on the degree of pressure decrease in the cycle has a maximum value. The maximum achievable microCHP efficiency lies in the range from 8.0 to $10.5 \%$.

It should be noted that increasing the gas temperature in front of the turbine $T_{3}$, the value $\pi_{t}$ is moved to the region of large values. When choosing the degree of pressure reduction, it seems reasonable to limit the quantity to $\pi_{t}=2.3 \ldots 2.4$ as this reduces the required rotor speed, simplifies the design and increases the reliability of the turbine installation. The microCHP maximum efficiency will be $\eta_{e}=7.0 \ldots 8.5 \%$.

According to the results obtained, shown in Fig. 4 and Fig. 5, it can be concluded that while still remaining a type of vehicles turbochargers (with the air consumption in the cycle $G=0.075 \ldots 0.25 \mathrm{~kg} / \mathrm{s})$, the generated electric power of the microCHP will be $N_{e}=$ $3.7 \ldots 15 \mathrm{~kW}$.

At the same time, the thermal power of such a unit will be $N_{t}=45 \ldots 160 \mathrm{~kW}$. The values obtained satisfy the requirements for all the categories of isolated thermal and electric energy consumers, presented in Table 1.

\section{Conclusion}

Based on the studies carried out, the following conclusions can be drawn:

- With a current of small-scale turbines design, it is possible to create a microCHP based on the microturbine with the changed order of processes with an efficiency at about $9 . .11 \%$, which is close to a low-power gas turbine unit of a simple cycle.

- When the air flow rate is $0.075 \ldots 0.25 \mathrm{~kg} / \mathrm{s}$, which is typical for vehicles turbochargers, the possible electrical power of microCHP based on the microturbine with the changed order of processes lies in the range 
from 1.6 to $15 \mathrm{~kW}$, the thermal power from 37 to 160 $\mathrm{kW}$.

- Parameters of microCHP based on the microturbine with the changed order of processes are sufficient to power supply low-rise housing.

The advantages of microCHP based on the microturbine with the changed order of processes are as follows: high ratio of $N_{t} / N_{e}>9$; a high utilization rate of the heat of the burned fuel $\eta_{i t}>90 \%$; basing on vehicles turbochargers proven technology; work on natural gas from low-pressure networks.

\section{References}

[1] Main characteristics of the Russian electric power industry. Official site of the Ministry of Energy of the Russian Federation [Electronic resource] Available at: https://minenergo.gov.ru

[2] Heat power and district heating in Russia, Materials of the Information and Analytical Report of the Federal State Budgetary Institution Russian Energy Agency of the Ministry of Energy of Russia [Electronic resource], Moscow (2018) Available at: https://www.rosteplo.ru/Tech_stat/stat_shablon.php ?id $=4078$

[3] Smart Grids European Technology Platform [Electronic resource] Available at: www.smartgrids.eu

[4] A.A. Zhinov, D.V. Shevelev, A.K. Karyshev, P.A. Anan'ev, The numerical research of the gas flow in the exhaust duct of the gas turbine with a waste heat boiler, Ain Shams Engineering Journal 9, 4, 1325-1334 (2018)

[5] Electronic resource Available at: https://www.sciencedirect.com/science/article/pii/S 2090447916301174

[6] L.M. Chamra, P.J. Mago, Micro-CHP Power Generation for Residental and Small Commercial Buildings (Nova Science Publishers, Inc. New York, 2009)

[7] E.G. Lipihin, D.V. Shevelev, Thermodynamic effective efficiency investigation for a micro-CHP system featuring a gas microturbine with an altered process sequence, Inzhenernyj zhurnal: nauka i innovacii [Engineering Journal: Science and Innovation] 10, 58 (2016) DOI: 10.18698/23086033-2016-10-1547 (in Russian)

[8] E.G. Lipihin, D.V. Shevelev, The influence of the turbine expansion ratiofor micro-CHP microturbine design, Nauka, tehnika I obrazovanie [Electronic journal: Science Technic and Education] 4, 9, 8-14 (2016) ISSN 2413-6220 Available at: http://ntojournal.ru/uploads/articles/dd483a8e53a91e9b338c 61c0e1114312.pdf (in Russian)

[9] GOST R 53637-2009, Automotive turbochargers. General technical requirements and test methods, Moscow, Standartinform, 12 (2010) (in Russian)

[10] W.P.J. Visser, S. Shakariyants, M.T.L. de Later, Performance optimization of a $3 \mathrm{kw}$ microturbine for chp applications, Proceedings of ASME Turbo Expo, 11 (11-15 June 2012)

[11] R. Kiyarash, M. Saad, K.Al-D. Raya, Development and experimental study of a small-scale compressed air radial inflow turbine for distributed power generation, Applied Thermal Engineering 116, 549-583 (2017)

[12] E.N. Kablov, Cast blades of gas turbine engines (alloys, technology, coating), 2-nd ed. (Moscow, Nauka [Science], 2006) 632 (in Russian)

[13] S.S. Berman, Raschet teploobmennykh apparatov [Calculation of heat exchangers] (Moscow, Gosenergoizdat [State Power Engineering Publishing House], 1962) 240 (in Russian)

[14] GE Power Systems selects GateCycle [Electronic resource] Available https://www.poweronline.com/doc/ge-powersystems-selects-gatecycle-0001 